\title{
An Effective of Dye Molecules with Cadmium Sulfide Nanorods in Dye Sensitized Solar Cell (DSSCs)
}

\author{
Entidhar Alkuam \\ Department of Physics and Astronomy, University of Arkansas at Little Rock, Little Rock, AR, USA \\ Email: eaalkum@ualr.edu
}

How to cite this paper: Alkuam, E. (2019) An Effective of Dye Molecules with Cadmium Sulfide Nanorods in Dye Sensitized Solar Cell (DSSCs). Advances in Materials Physics and Chemistry, 9, 37-47.

https://doi.org/10.4236/ampc.2019.94004

Received: March 5, 2019

Accepted: April 16, 2019

Published: April 19, 2019

Copyright $\odot 2019$ by author(s) and Scientific Research Publishing Inc. This work is licensed under the Creative Commons Attribution International License (CC BY 4.0).

http://creativecommons.org/licenses/by/4.0/

\begin{abstract}
The aligned hexagonal cadmium sulfide nanorods $\left(\mathrm{CdS}_{\mathrm{NR}}\right)$ have been synthesized by hydrothermal technique at $200^{\circ} \mathrm{C}$ on fluorine tin oxide (FTO) substrates. Dye sensitized solar cells (DSSCs) based on the photoelectrode core-shell $\mathrm{CdS}_{\mathrm{NR}}$ array with conductive polymers nanocomposite of polyaniline (PANI) and poly(3,4-ethylenedioxyl-thiophene)/poly(styrene-sulfonate) (PEDOT:PSS) were fabricated and designed with different types of dye molecules. DSSCs were characterized utilizing scanning electron microscopy (SEM), Raman scattering, energy dispersive spectroscopy (EDS), UV-Vis absorption spectroscopy, X-ray diffraction (XRD), and photocurrent-voltage (J-V) characteristic. Results show that under illumination (AM 1.5 G), the high power conversion energy (PCE) was achieved for $\mathrm{CdS}_{\mathrm{NR}} / \mathrm{PANI}-\mathrm{PEDOT}$ :PSS device when it sensitized with ruthenium (II) (dye N-719) of $0.91 \%$ and a short circuit current density (Jsc) of $4.21 \mathrm{~mA} / \mathrm{cm}^{2}$ in comparison with the other devices, which sensitized with natural dyes. The high performance of the $\mathrm{CdS}_{\mathrm{NR}} /$ PANI-PEDOT:PSS-N719 device attributed to the wide range of absorption and photostability for N719. This work shows that the $\mathrm{CdS}_{\mathrm{NR}}$ with N719 can be appropriate candidate for photovoltaics device for their low cost fabrication procedure and excellent absorption.
\end{abstract}

\section{Keywords}

Cadmium Sulfide Nanorods, Hydrothermal Process, PANI, PEDOT:PSS, DSSCs, Natural Dye, Ruthenium (II) (Dye N719)

\section{Introduction}

Because of encouraging photo-conversion efficiency (PCE), dye sensitized solar 
cells (DSSCs) have been widely studied over the past twenty years [1]. Especially in the case of smaller market segments, DSSCs signify a workable substitute for silicon-based solar cells. Alongside serviceable PCEs, they offer low fabrication costs, environmentally-responsible constituents and a simple fabrication process. Discoveries in such as innovative dyes and electrolytes over the past several years have regenerated attention for such devices, and have increased the PCE to as high as $14 \%$ [1] [2] [3].

DSSC function begins with photo-excitation of a dye molecule, the light harvesting or charge-generation step as shown in Figure 1. Next comes injection of an electron into the nanostructural conduction band of any of several wide-bandgap metal oxides (the transport of charge carriers). The oxidized dye molecule is subsequently regenerated back to its ground state by accepting a single electron from an electrolyte that saturates the sensitized nano-structured metal oxide film (electrons in the n-type metal oxide move into holes in the electrolyte). The DSSCs concept requires three properly separated materials: a photo-sensitive dye, a metal oxide, and an electrolyte [4] [5].

The photo-absorptive dye, which generates excitons, is bonded to the surface of a semiconductor layer. The high PCE of DSSCs using ruthenium (II)-polypyridyl complexes (13\% under standard illumination) can be credited to their photo-stability in the finished solar cell, wide absorption range, and generous spectroscopic properties [6].

Although commercially available DSSCs using ruthenium bipyridyl-based dyes (N3 dyes or N917) attained PCEs above 10\% as early as 1993 [7] [8], these are expensive and hard to store dyes [8] [9]. A group at the University of Bahrain used methanol solvent in the Soxhlet Extraction Apparatus to develop environmentally-safe dyes from profuse natural sources. These included Bahraini Henna (Lawsonia inermis L.), dried cherries, pomegranate, raspberries, and Yemeni Henna, (Jasim, submitted for publication 2011) [8].

CdS has become a vital material for many types of optical devices, including solar cells [10]. It is broadly acknowledged that many physical CdS aspects will enhance or diminish its photocatalytic yield. Its crystalline phase, structural defects, specific surface area, and size and morphology of particles have all been

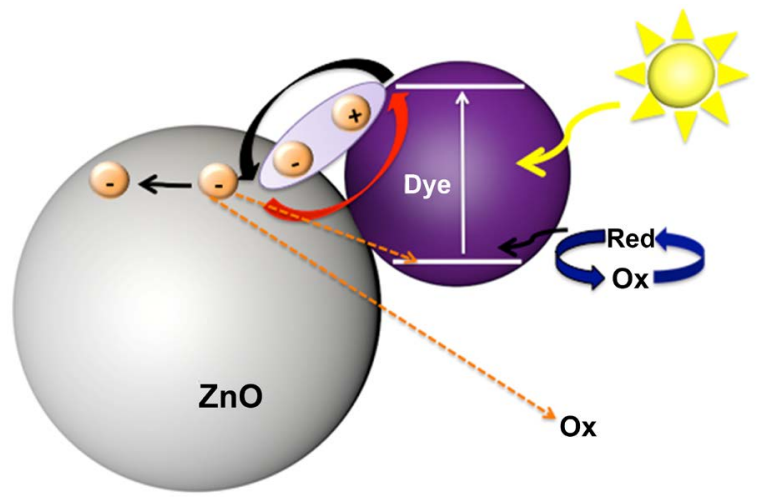

Figure 1. Schematic structure of $\mathrm{ZnO}$-based DSSCs. 
noted. Control over the size and shape of CdS particles is a crucial aspect of generating an energetic photocatalyst [11]. Therefore, various new techniques have been developed for formulating and producing CdS constituent parts. Bao et al. [12] [13] prepared nanoporous CdS nanostructures with an increased hydrogen yield under visible light, by using self-templated synthesis. Many other techniques have been successfully tapped to generate CdS nanostructures, including biogenic synthesis [12] [14], chemical bath deposition [15] [16] [17] [18], hydrothermal methods [5] [19] [20] [21], and thermal evaporation [22]. Of these, hydrothermal synthesis has proven an effective method for low temperature generation of nanostructures [11].

Yang et al. [6] reported improved efficiencies in electron transport and photon absorption with 1-D nanostructures including nanowires (NWs) and nanorods (NRs) [23].

Yoshimura defines hydrothermal processing as a homogeneous (nanoparticles) or heterogeneous (bulk materials) reaction carried out under high temperature and pressure using aqueous solvents or mineralizers in order to dissolve and recrystallize materials that are comparatively insoluble under usual conditions [19].

The hydrothermal deposition of CdS proceeds from the cadmium and sulfide ions in the solution and the chemical deposition can be accomplished using these reactions:

$$
\begin{gathered}
\left(\mathrm{NH}_{2}\right)_{2} \mathrm{CS}+\mathrm{H}_{2} \mathrm{O} \rightarrow\left(\mathrm{NH}_{2}\right)_{2} \mathrm{CO}+\mathrm{H}_{2} \mathrm{~S} \\
\mathrm{CdCl}_{2}+\mathrm{H}_{2} \mathrm{~S} \rightarrow \mathrm{CdS}+2 \mathrm{HCl}
\end{gathered}
$$

This direct ionic reaction yields a high-quality thin film notably free of impurities [20].

In this work, $\mathrm{CdS}_{\mathrm{NR}}$ photoanode with a large surface area were fabricated with a counter electrode of PANI-PEDOT:PSS nanocomposites to improve the performance of DSSCs via a low cost and simple deposition techniques. And the $\mathrm{CdS}_{\mathrm{NR}}$ photoelectrode was sensitized with three types of dye (N-719, BB, and $\mathrm{BE})$, the (N-719) dye sensitized $\mathrm{CdS}_{\mathrm{NR}}$-PANI-PEDOT:PSS device showed the highest PCE $(0.91 \%)$ due to capturing more photons from sunlight.

\section{Experimental Methods}

\subsection{Reagents}

Di-tetrabutylammonium cis-bis(isothiocyanato)bis

(2,2-bipyridyl-4,4-dicarboxylato)ruthenium(II) (N-719 dye) $\mathrm{C}_{58} \mathrm{H}_{86} \mathrm{~N}_{8} \mathrm{O}_{8} \mathrm{RuS}_{2}$ 95\%, Ethylene glycol $\left(\mathrm{CH}_{2} \mathrm{OH}\right)_{2}$, thiourea $\geq 99.0 \%$, poly(3,4-ethylenedioxyl-thiophene)/poly(styrene-sulfonate) PEDOT:PSS,

L-Glutathione reduced $\geq 98.0 \%$, were purchased from Sigma Aldrich. Fluorine doped tin oxide (FTO) coated glass substrate, with a resistivity of $12-17 \Omega \cdot \mathrm{cm}$ was purchased from Nanocs, iodine $\mathrm{I}_{2}$ was from mallinckodi chemical work. Cadmium nitrate $\mathrm{Cd}\left(\mathrm{NO}_{3}\right)_{2} \cdot 4 \mathrm{H}_{2} \mathrm{O}$, acetone $\left(\mathrm{C}_{3} \mathrm{H}_{6} \mathrm{O}\right)$, potassium iodide $(\mathrm{KI})$, and ethanol $\left(\mathrm{C}_{2} \mathrm{H}_{6} \mathrm{O}\right)$ were purchased from Fisher Scientific, sulfuric acid $\mathrm{H}_{2} \mathrm{SO}_{4}$, and 
aniline $\mathrm{C}_{6} \mathrm{H}_{7} \mathrm{~N} \geq 99 \%$ were purchased from Alfa Aesar. All the chemicals were utilized without further purification.

\subsection{Synthesis of $\mathrm{CdS} \mathrm{S}_{\mathrm{NR}}$ Precursor and Thin Film Deposition}

$\mathrm{CdS}_{\mathrm{NR}}$ were deposited via a hydrothermal process on FTO substrates, which were ultrasonically cleaned for few minutes with acetone, ethanol, and deionized water (DI with purity $18.20 \mathrm{M} \Omega \cdot \mathrm{cm}$ ). Ina typical deposition, $0.449 \mathrm{~g}$ of $\mathrm{Cd}\left(\mathrm{NO}_{3}\right)_{2} \cdot 4 \mathrm{H}_{2} \mathrm{O}$ was dissolved in $30 \mathrm{ml}$ of DI and stirred for 5 minutes at room temperature until get a clear precursor solution, on the other hand $0.109 \mathrm{~g}$, and $0.258 \mathrm{~g}$ from thiourea and L-Glutathione reduced were dissolved in $30 \mathrm{ml}$ of DI each respectively until clear solutions were obtained, a clear mixture of these three solutions was achieved. FTO substrate was vertically placed in a $20 \mathrm{ml}$ Teflon lined stainless steel autoclave which was contained the final solution, and the deposition was carried out at $200^{\circ} \mathrm{C}$ for 3.5 hours. Then cooled the autoclave to the room temperature and rinse the resultant sample with DI [5] [24]. Figure 2 illustrates the whole steps of deposition and fabricated DSSCs.

\subsection{Synthesis of PANI, PEDOT:PSS, Electrolyte, and Dye}

Pristine PANI fabricated by dissolving aniline monomer (2 M) in sulfuric acid (1 M) under continuous stirring for 5 minutes, the electrochemical polymerization occurred at $2 \mathrm{~V}$ at room temperature on cleaned FTO, then rinsed a PANI thin film with the DI [5].

PEDOT:PSS was spin coated on PANI/FTO, the PEDOT:PSS solution with 3 vol\% ethanol to improve the conductivity of it [18], was stirred for 1 hour and then filtered. Then the PEDOT:PSS layer annealed on $150^{\circ} \mathrm{C}$ hot plate for few minutes.

To prepare the electrolyte, $0.83 \mathrm{~g}$ of potassium iodide and $0.127 \mathrm{~g}$ of iodine were dissolved in $10 \mathrm{ml}$ of ethylene glycol under stirred.

For dye preparation, $0.01 \mathrm{~g}$ of ruthenium (II) (N-719 dye) was dissolved in 20 $\mathrm{ml}$ of ethanol. While for natural dye of black berry dye (BB), and beet dye (BE) preparation, add amount of ethanol and vinegar to clean $\mathrm{BB}$ or BE juice as shown in Figure 2. Then the n-type electrode $\left(\mathrm{CdS}_{\mathrm{NR}}\right)$ was immersed a bath of dye for 10 hours.

\subsection{Solar Cell Fabrication}

DSSCs devices were fabricated with the structure of FTO/CdS $\mathrm{SR}_{\mathrm{NR}} / \mathrm{PANI}-\mathrm{PEDOT}$ : PSS/FTO as shown in Figure 3. The photoanode for the DSSCs was $\mathrm{CdS}_{\mathrm{NR}}$ sensitized with three types of dye molecules (N-719, BB, and BE), while the counter electrode was PANI-PEDOT:PSS nanocomposites, an iodine electrolyte filled the inner area of the spacer $0.9 \times 0.9 \mathrm{~cm}^{2}$ which is represented the illuminated area, while the outer area of the spacer was $2.5 \times 2.5 \mathrm{~cm}^{2}$.

\section{Characterization Methods}

X-ray diffraction (XRD; Rigaku Miniflex $600 \mathrm{X}$-ray diffractometer utilizing $\mathrm{CuK}_{a}$ 


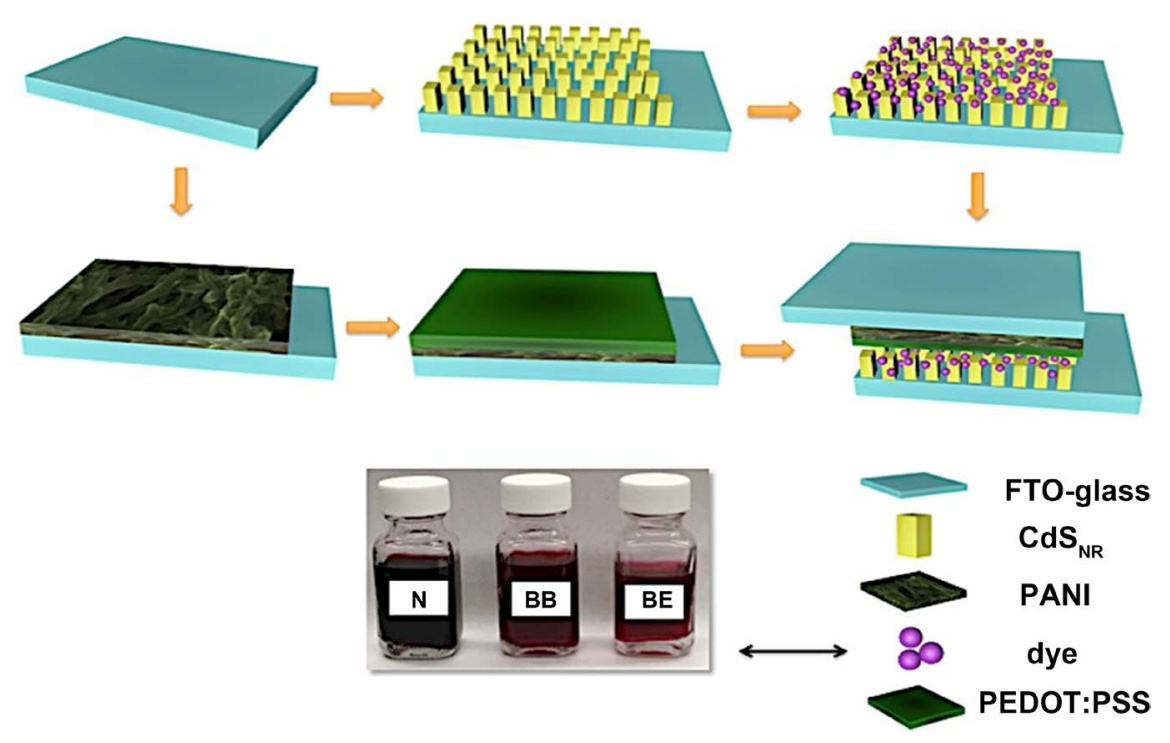

Figure 2. General procedure utilized to prepare a sandwich device of DSSCs.

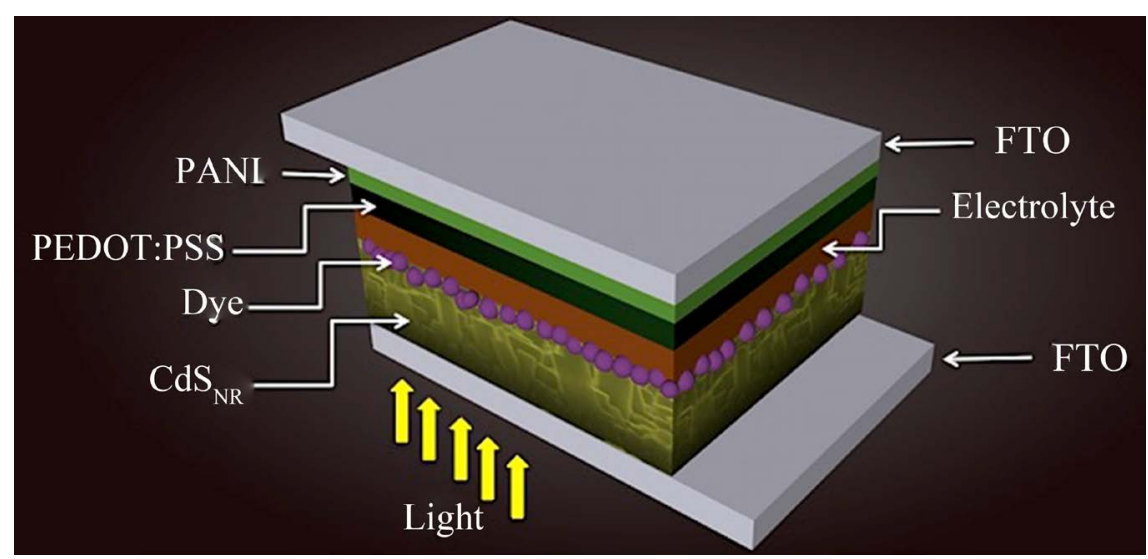

Figure 3. The schematic diagram of FTO/CdS $\mathrm{NR}_{\mathrm{NR}}$ PANI-PEDOT:PSS/FTO device.

radiation with a wavelength $1.54056 \AA$ ) was acquired to perform the crystalline and phase identification of $\mathrm{CdS}_{\mathrm{NR}}$. Scanning Electron Microscopy (SEM, JEOL JSM7000F) was used to investigate the surface morphologies of the samples, and the $\mathrm{CdS}_{\mathrm{NR}}$ composition was observed by energy dispersive X-ray analysis (EDX). UV-visible spectrometer was used to record UV-vis absorbance spectra from 300 $-1000 \mathrm{~nm}$.

For the analysis of the DSSCs, current voltage (I-V) analysis by Keithley Model 2400 sourcemeter (which was calibrated with a standard Si solar cell) was used under a simulated AM $1.5 \mathrm{G}$ spectrum at room temperature. EZRaman-N was acquired using to find Raman spectra.

\section{Mechanism of DSSCs}

$\mathrm{CdS}_{\mathrm{NR}}$ was used as photoelectrode, and PANI-PEDOT:PSS nanocomposites was used as counter electrode of DSSCs. The space between the anode and cathode was filled with Iodide electrolyte containing $\mathrm{I}^{-} / \mathrm{I}_{3}^{-}$redox. When the DSSCs is il- 
luminated by light, the photoexcitation was happened in the dye molecules, and the electron will be excited from the highest occupied molecular orbital (HOMO) to the lowest molecular orbital (LUMO) states of dye molecules as shown in Figure 4. Then the electron injected transfer to the conduction band (CB) of $\mathrm{CdS}_{\mathrm{NR}}$ which cause to oxidize the dye molecules, the dye molecules will be regenerated from the reduced state of the electrolyte containing redox couple, which is regenerated by receiving electron from counter electrode.

\section{Results and Discussion}

Figures 5(a)-(e) show the typical SEM images of $\mathrm{CdS}_{\mathrm{NR}}$ which was synthesized by hydrothermal. Figure 5(a) and Figure 5(b) investigate the top view of $\mathrm{CdS}_{\mathrm{NR}}$ at micro and nano magnification, it is clearly shown that the large scale nanorods covered the substrate with highly ordered surface area, these nanorods have an average length of $\sim 600 \mathrm{~nm}$, and diameter of $\sim 100 \mathrm{~nm}$ as shown in Figure 5(b), Figure 5(d), and Figure 5(e). It is obviously seen that the surface uniformly covered with a $\mathrm{CdS}_{\mathrm{NR}}$ as presented in the SEM image in Figure 5(c). The EDS spectra for Cd and S are shown in Figure 6(c). The elemental composition of Cd and S from EDS is $49.0 \%$ and $51.0 \%$ respectively.

Figure 5(f) and Figure 5(g) present the SEM images of PANI thin film at low and high magnification, a nanofiber structure of pristine PANI, and presence some pores in the film can be clearly shown from the SEM images. PEDOT:PSS coated on PANI in order to improve the electrical conductivity of PANI [25] [26], the surface of PEDOT:PSS and organized chains are shown in Figure 5(h) and Figure 5(i).

Figure 6(a) compares the absorbance of the $\mathrm{CdS}_{\mathrm{NR}}$ and sensitized $\mathrm{CdS}_{\mathrm{NR}}$ with different types of dye (N719, BB, and BB). Apparently $\mathrm{CdS}_{\mathrm{NR}}$ sensitization with N719 have an improvement in light harvest, and the maximum absorbance of $\mathrm{CdS}_{\mathrm{NR}}+\mathrm{N} 719$ than the $\mathrm{CdS}_{\mathrm{NR}}$ sensitized with dye BB or BE, which in turns indicateto a good light absorption and an effective electron injection [4]. The variance between the curves is due to light absorbance by the dye (N719, BB, and

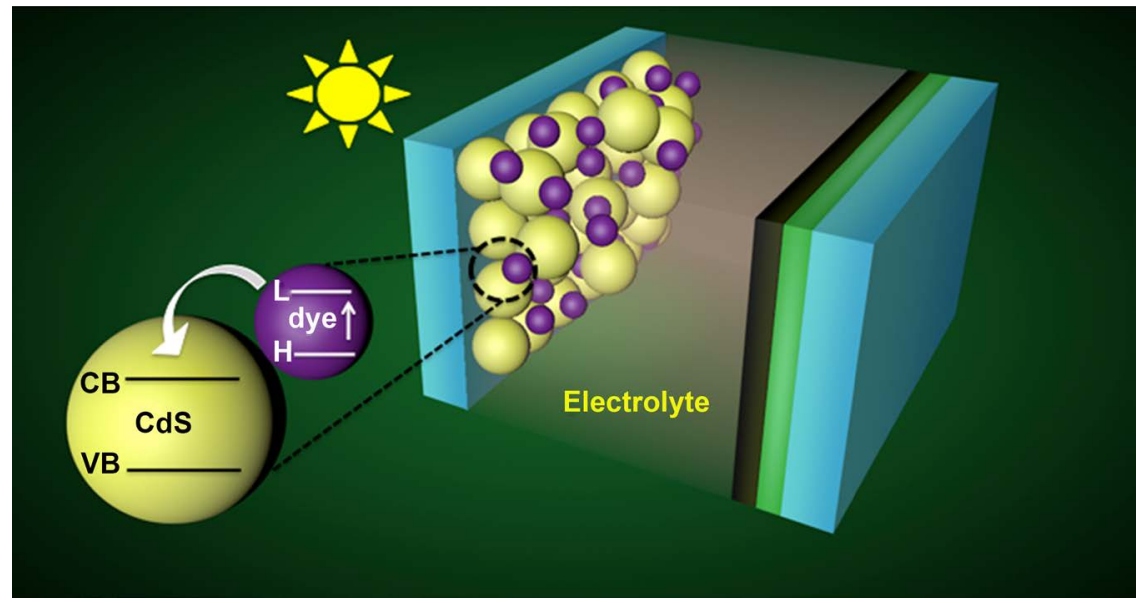

Figure 4. The mechanism of DSSCs. 

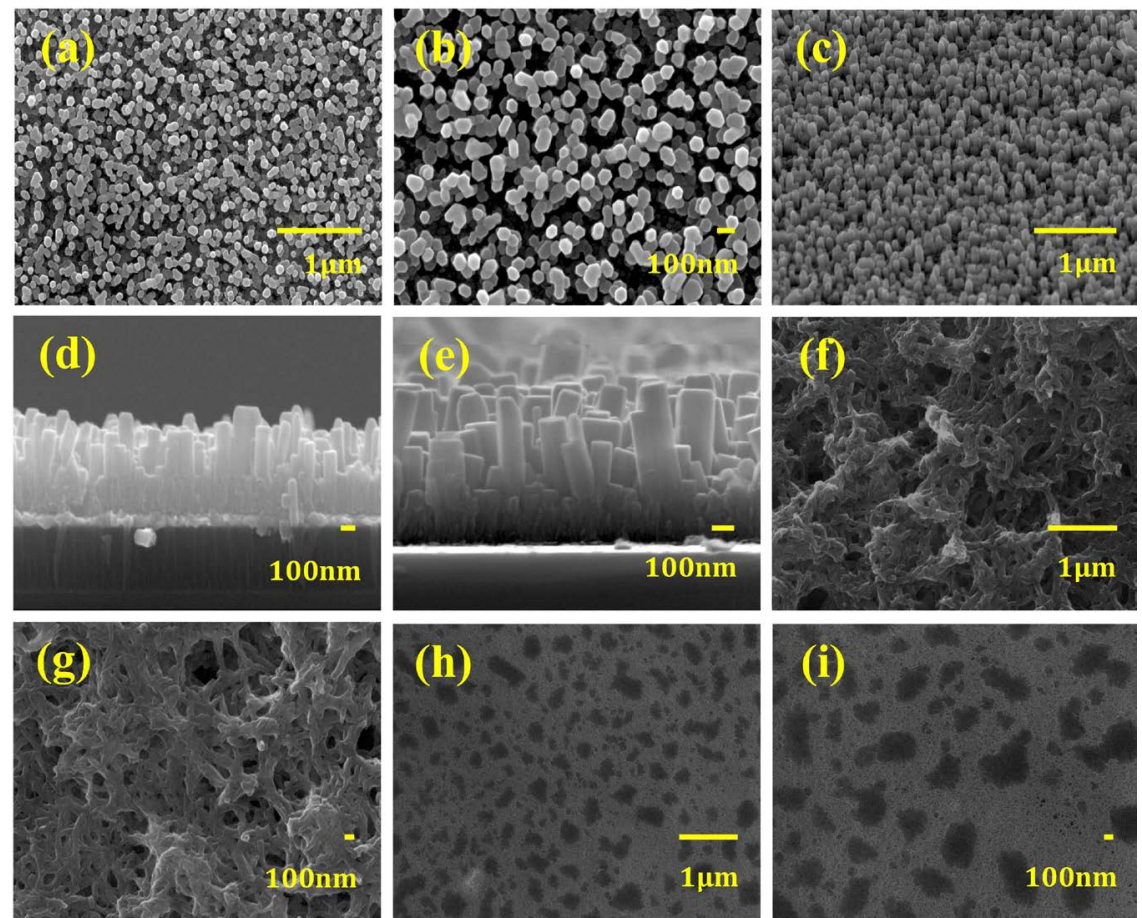

Figure 5. Top view and cross section SEM images of $\mathrm{CdS}_{\mathrm{NR}}$ (a)-(e), micro and nano magnification of PANI (f)-(g), and micro and nano magnification of PEDOT:PSS (h)-(i).
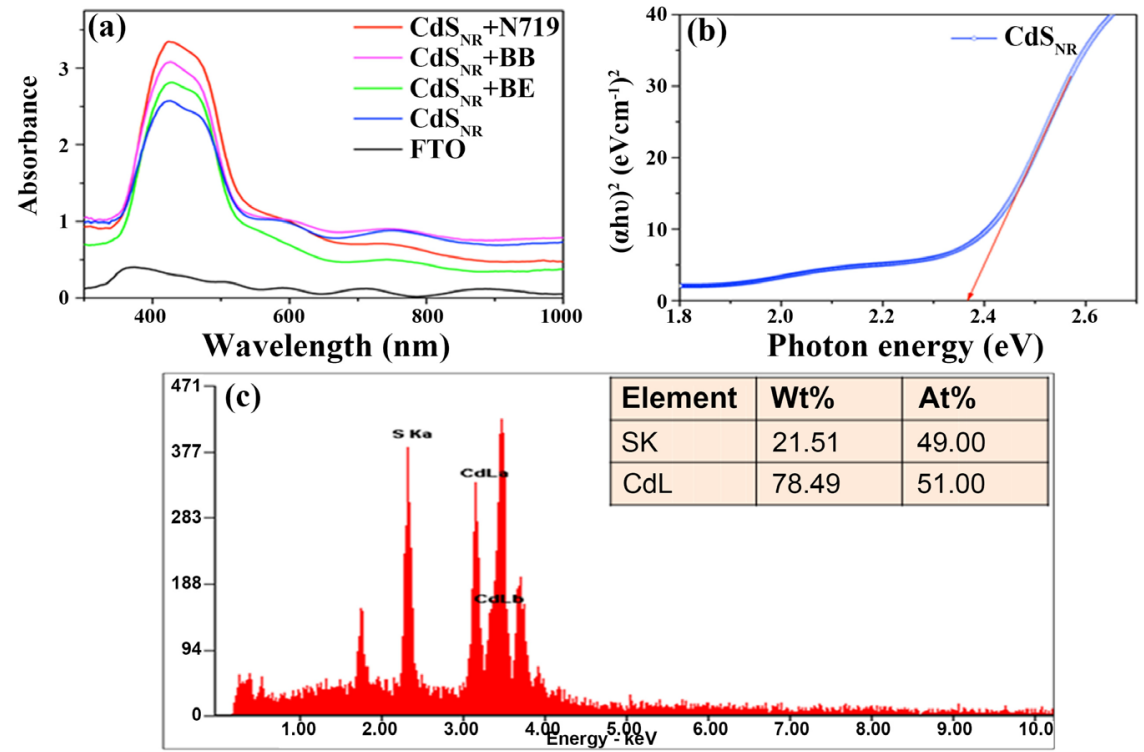

Figure 6. Absorbance spectra of the $\mathrm{CdS}_{\mathrm{NR}}$, sensitized $\mathrm{CdS}_{\mathrm{NR}}$ with different types of dye (N719, BB, and BB), and FTO (a) band gap of $\mathrm{CdS}_{\mathrm{NR}}$ (b), and EDS plot-data for $\mathrm{CdS}_{\mathrm{NR}}$ (c).

$\mathrm{BB})$. The maximum absorbance of $\mathrm{CdS}_{\mathrm{NR}}+\mathrm{N} 719$ in the visible region is at 420 $\mathrm{nm}$. It was found that the band gap of $\mathrm{CdS}$ to be $2.36 \mathrm{eV}$ as shown in Figure 6(b).

Figure 7(a) shows XRD patterns of the $\mathrm{CdS}_{\mathrm{NR}}$ and FTO. The hexagonal phase and the crystallinity of the $\mathrm{CdS}_{\mathrm{NR}}$ increase significantly as shown from the XRD 

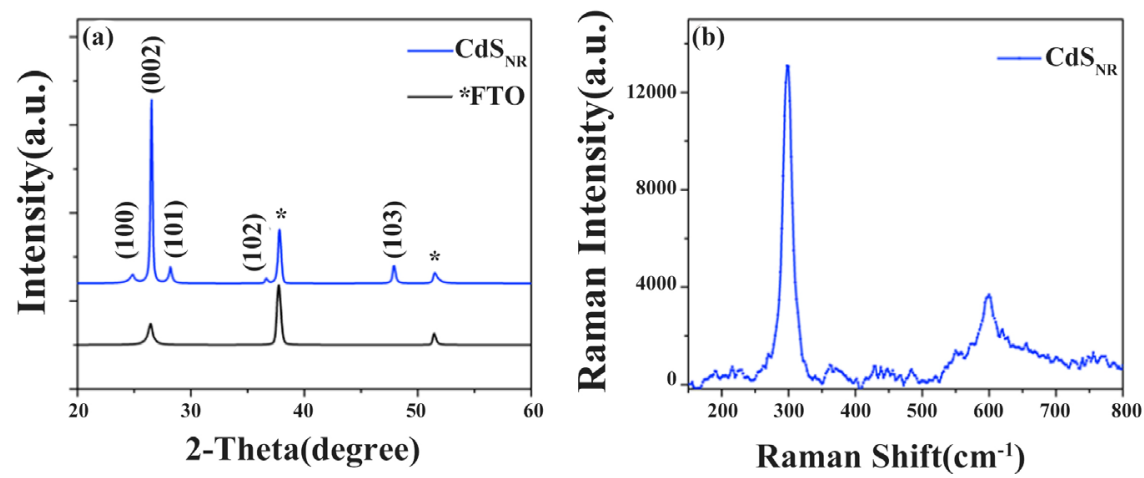

Figure 7. XRD pattern of $\mathrm{CdS}_{\mathrm{NR}}$ and FTO (a), and Raman spectrum of $\mathrm{CdS}_{\mathrm{NR}}(\mathrm{b})$.

patterns. The crystallite size of $\mathrm{CdS}_{\mathrm{NR}}$ has been calculated by the XRD line broadening from Debye-Scherrer's equation as follows [27] [28] [29]:

$$
L=\frac{K \lambda}{\beta \cos \theta}
$$

where $\mathrm{D}$ is the crystallite size, $\lambda$ is the wavelength of the $\mathrm{X}$-ray radiation in nanometer (nm), $\theta$ the diffraction angle, $\beta$ is the full width at the half maximum of the peak (FWHM), and $K$ is a constant (0.9). The measurements referred that the mean crystallite sizefor the diffraction $\mathrm{H}(002)$ for $\mathrm{CdS}_{\mathrm{NR}}$ was $50.84 \pm 6 \mathrm{~nm}$.

The Raman scattering spectra from the $\mathrm{CdS}_{\mathrm{NR}}$ are illustrated in shown in Figure 7(b). Peaks at $300 \mathrm{~cm}^{-1}$ and at $600 \mathrm{~cm}^{-1}$ correspond to fundamental longitudinal optical phonon (1LO), and the first overtone mode (2LO). The high intensity refers to the increasing in the thickness, which in turns has better crystallinty.

Figure 8(a) and Figure 8(b) show the current density (J)-voltage (V) characteristics of DSSCs under illumination (AM $1.5 \mathrm{G}, 100 \mathrm{~mW} / \mathrm{cm}^{2}$ ) and under dark respectively.

The performance of dye N719, BB, and BE sensitizer have been studied, and the data of open circuit voltage $\left(V_{o c}\right)$, short circuit current density $\left(J_{s c}\right)$, fill factor $(F F)$, series resistance $\left(R_{s}\right)$, shunt resistance $\left(R_{s h}\right)$, and power conversion efficiency $(\eta)$ are shown in shown in Table 1 . It has been found that the $\mathrm{CdS}_{\mathrm{NR}}$ are very effective when sensitized with ruthenium dye N719 which enhanced the light harvesting, and thus the maximum absorption would lead to photocurrent of $4.21 \mathrm{~mA} / \mathrm{cm}^{2}$, and high power conversion efficiency of $0.91 \%$ due to reduced recombination and increased charge injections. On the other hand low absorption caused in reduction in the short circuit photocurrent of $2.20 \mathrm{~mA} / \mathrm{cm}^{2}$, and $0.6721 \mathrm{~mA} / \mathrm{cm}^{2}$ in the devices, which were sensitized with $\mathrm{BB}$, and $\mathrm{BE}$ respectively and then effected on the performance of the solar cell. The high value of $R_{s h}=30 \Omega \cdot \mathrm{cm}^{2}$ and low value of $R_{s}=8.13 \Omega \cdot \mathrm{cm}^{2}$ can be affected on the performance of DSSCs. The DSSCs efficiency calculated from the equation [5] [18] [30]:

$$
\eta=\left(\frac{\mathrm{FF} \cdot \mathrm{J}_{\mathrm{sc}} \cdot \mathrm{V}_{\mathrm{oc}}}{\mathrm{P}_{\mathrm{in}}}\right)
$$


Table 1. I-V Characterization of devices structures under illumination of AM 1.5.

\begin{tabular}{ccccccc}
\hline Devices & $\mathrm{J}_{\mathrm{SC}}\left(\mathrm{mA} / \mathrm{cm}^{2}\right)$ & $\mathrm{V}_{\mathrm{OC}}(\mathrm{V})$ & $\mathrm{FF}(\%)$ & $\mathrm{R}_{\mathrm{Sh}}\left(\Omega \cdot \mathrm{cm}^{2}\right)$ & $\mathrm{R}_{\mathrm{S}}\left(\Omega \cdot \mathrm{cm}^{2}\right)$ & PCE $(\%)$ \\
\hline $\mathrm{CdS}_{\mathrm{NR}} /$ PANI-PEDOT:PSS-N719 & 4.21 & 0.53 & 37 & 30 & 8.13 & 0.91 \\
$\mathrm{CdS}_{\mathrm{NR}} /$ PANI-PEDOT:PSS-BB & 2.20 & 0.58 & 39 & 77 & 4.25 & 0.614 \\
$\mathrm{CdS}_{\mathrm{NR}} /$ PANI-PEDOT:PSS-BE & 0.67 & 0.50 & 20 & 55 & 26.95 & 0.056 \\
\hline
\end{tabular}
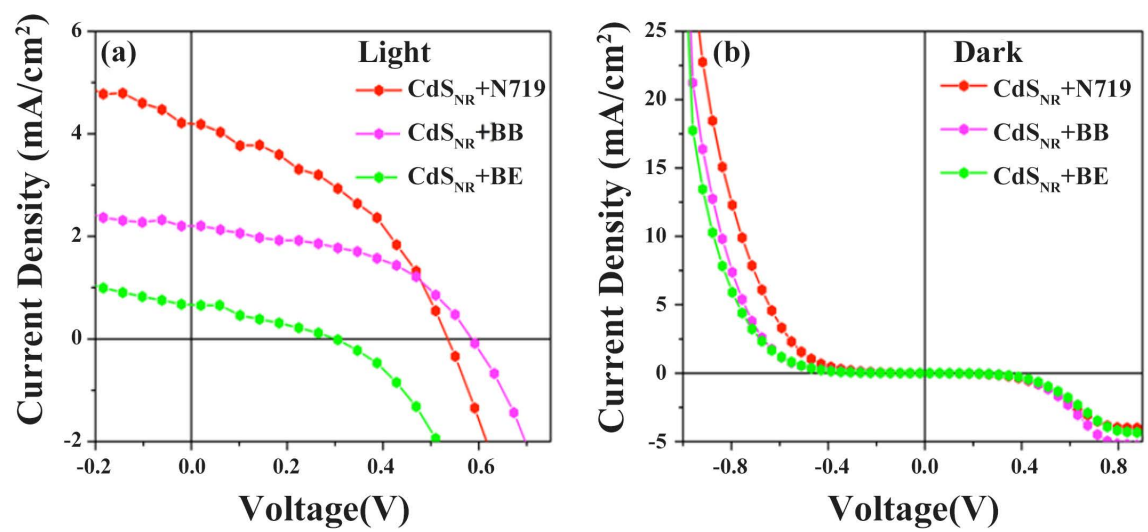

Figure 8. The J-V Characteristics of $\mathrm{CdS}_{\mathrm{NR}} /$ PANI-PEDOT:PSS-N719, $\mathrm{CdS}_{\mathrm{NR}} / \mathrm{PANI}-\mathrm{PEDOT}$ :PSS-BB, and $\mathrm{CdS}_{\mathrm{NR}} / \mathrm{PANI}-\mathrm{PEDOT}$ :PSS-BE devices (a) under AM1.5 G illumination and (b) in the dark.

\section{Conclusion}

DSSCs based on $\mathrm{CdS}_{\mathrm{NR}}$ photoelectrode were fabricated with simple hydrothermal deposition technique. The low cost and natural dyes were used as the sensitizer such BB, and BE. Also, the dye ruthenium N719 was used as a sensitizer. The high performance can be attributed to the large surface area, high harvesting of photons when the dye ruthenium N719 was used as a sensitizer, low recombination, and high quality crystal size, due to using hexagonal wurtzite CdS.

\section{Acknowledgements}

Entidhar would like to thank the Department of Physics and Astronomy, College of Arts, Litters, and Sciences, University of Arkansas at Little Rock for its assistance. Thanks for Center for Integrative Nanotechnology Sciences at University of Arkansas at Little Rock for helping with SEM, and Dr. Wissam M. Alobaidi for his support.

\section{Conflicts of Interest}

The author declares no conflicts of interest regarding the publication of this paper.

\section{References}

[1] Benetti, D., Dembele, T., Benavides, J. and Zhao, H. (2016) Functionalized Multi-Wall Carbon Nanotubes/ $\mathrm{TiO}_{2}$ Composites as Efficient Photoanodes for Dye Sensitized Solar Cells Daniele. Journal of Materials Chemistry C, 4, 3555-3562. https://doi.org/10.1039/C6TC00800C 
[2] Misra, M., Singla, M. L., Kapur, P. and Ghansyam, C. (2012) Compact Packing of CdS Nanoparticle in Flower Like $\mathrm{TiO}_{2}$ Nanorods for DSSC Solar Cell. International Conference in Devices, Circuits and Systems, Coimbatore, 15-16 March 2012, 548-549.

[3] Alkuam, E., Badradeen, E. and Guisbiers, G. (2018) Influence of CdS Morphology on the Efficiency of Dye-Sensitized Solar Cells. ACS Omega, 3, 13433-13441. https://doi.org/10.1021/acsomega.8b01631

[4] Anta, J.A. and Guille, E. (2012) ZnO-Based Dye-Sensitized Solar Cells. The Journal of Physical Chemistry C, 116, 11413-11425. https://doi.org/10.1021/jp3010025

[5] Alkuam, E., Mohammed, M. and Chen, T.-P. (2017) Fabrication of CdS Nanorods and Nanoparticles with PANI for (DSSCs) Dye-Sensitized Solar Cells. Solar Energy, 150, 317-324. https://doi.org/10.1016/j.solener.2017.04.056

[6] Mehmood, U., Hussein, I.A., Harrabi, K., Mekki, M.B., Ahmed, S. and Tabet, N. (2015) Hybrid $\mathrm{TiO}_{2}$-Multiwall Carbon Nanotube (MWCNTs) Photoanodes for Efficient Dye Sensitized Solar Cells (DSSCs). Solar Energy Materials \& Solar Cells, 140, 174-179. https://doi.org/10.1016/j.solmat.2015.04.004

[7] Nazeeruddin, M.K., Kay, A., Rodicio, I., Humphry-Baker, R., Mueller, E., Liska, P., et al. (1993) Conversion of Light to Electricity by SCN on Nanocrystalline $\mathrm{TiO}_{2}$ Electrodes. Journal of the American Chemical Society, 115, 6382-6390. https://doi.org/10.1021/ja00067a063

[8] Jasim, K.E. (2011) Dye Sensitized Solar Cells-Working Principles, Challenges and Opportunities. In: Solar Cells-Dye-Sensitized Devices, InTech, London, 171-204.

[9] Cherepy, N.J., Smestad, G.P., Gra, M. and Zhang, J.Z. (1997) Ultrafast Electron Injection: Implications for a Photoelectrochemical Cell Utilizing an Anthocyanin Dye-Sensitized $\mathrm{TiO}_{2}$ Nanocrystalline Electrode. The Journal of Physical Chemistry $B, 101,9342-9351$. https://doi.org/10.1021/jp972197w

[10] Chuu, D.S., Dai, C.M., Hsieh, W.F. and Tsai, C.T. (1991) Raman Investigations of the Surface Modes of the Crystallites in CdS Thin Films Grown by Pulsed Laser and Thermal Evaporation. Journal of Applied Physics, 69, 8402-8404. https://doi.org/10.1063/1.347405

[11] Li, Y., Hu, Y., Peng, S., Lu, G. and Li, S. (2009) Synthesis of CdS Nanorods by an Ethylenediamine Assisted Hydrothermal Method for Photocatalytic Hydrogen Evolution. The Journal of Physical Chemistry C, 113, 9352-9358. https://doi.org/10.1021/jp901505j

[12] Su, J., Zhang, T., Li, Y., Chen, Y. and Liu, M. (2016) Photocatalytic Activities of Copper Doped Cadmium Sulfide Microspheres Prepared by a Facile Ultrasonic Spray-Pyrolysis Method. Molecules, 21, 735. https://doi.org/10.3390/molecules21060735

[13] Bao, N., Shen, L., Takata, T. and Domen, K. (2008) Self-Templated Synthesis of Nanoporous CdS Nanostructures for Highly Efficient Photocatalytic Hydrogen Production under Visible Light. Chemistry of Materials, 20, 110-117. https://doi.org/10.1021/cm7029344

[14] Tripathi, R.M., Bhadwal, A.S. and Singh, P. (2014) Mechanistic Aspects of Biogenic Synthesis of CdS Nanoparticles Using Bacillus Licheniformis. Advances in Natural Sciences: Nanoscience and Nanotechnology, 5, Article ID: 025006. https://doi.org/10.1088/2043-6262/5/2/025006

[15] Oladeji, I.O. and Chow, L. (1997) Optimization of Chemical Bath Deposited Cadmium Sulfide Thin Films. Journal of the Electrochemical Society, 144, 2342-2346. https://doi.org/10.1149/1.1837815

[16] Mondal, A., Chaudhuri, T.K. and Pramanik, P. (1983) Deposition of Cadmium 
Chalcogenide Thin Films by a Solution Growth Technique Using Triethanolamine as a Complexing Agent. Solar Energy Materials, 7, 431-438. https://doi.org/10.1016/0165-1633(83)90016-3

[17] Choi, J.Y., Kim, K.-J., Yoo, J.-B. and Kim, D. (1998) Properties of Cadmium Sulfide Thin Films Deposited by Chemical Bath Deposition with Ultrasonication. Solar Energy, 64, 41-47. https://doi.org/10.1016/S0038-092X(98)00047-4

[18] Alkuam, E., Mohammed, M. and Chen, T. (2017) Enhanced Synthesis of Cadmium Sulfide by Electrodeposition in Dye-Sensitized Solar Cells. Solar Energy, 157, 342-348. https://doi.org/10.1016/j.solener.2017.08.052

[19] Yoshimura, M and Byrappa, K. (2008) Hydrothermal Processing of Materials: Past, Present and Future. Journal of Materials Science, 43, 2085-2103. https://doi.org/10.1007/s10853-007-1853-x

[20] Holi, A.M., Zainal, Z. and Talib, Z.A. (2016) Hydrothermal Deposition of CdS on Vertically Aligned ZnO Nanorods for Photoelectrochemical Solar Cell Application. Journal of Materials Science: Materials in Electronics, 27, 7353-7360. https://doi.org/10.1007/s10854-016-4707-y

[21] Phuruangrat, A., Thongtem, T. and Thongtem, S. (2009) Characterisation of One-Dimensional CdS Nanorods Synthesised by Solvothermal Method. Journal of Experimental Nanoscience, 4, 47-54. https://doi.org/10.1080/17458080802654486

[22] Abdulelah, H., et al. (2016) Fabrication and Characterization of Porous CdS/Dye Sensitized Solar Cells. Solar Energy, 1-7.

[23] Ragam, M., Sankar, N. and Ramachandran, K. (2013) Charge Transport in 1-D Nanostructured CdS Dye Sensitized Solar Cell. Journal of Nanoscience, 2013, Article ID: 167517.

[24] Chen, F., Qiu, W.M., Chen, X.Q., Yang, L.G., Jiang, X.X., Wang, M., et al. (2011) Large-Scale Fabrication of CdS Nanorod Arrays on Transparent Conductive Substrates from Aqueous Solutions. Solar Energy, 85, 2122-2129. https://doi.org/10.1016/j.solener.2011.05.020

[25] Lee, H.J., Anoop, G., Lee, H.J., Kim, C., Park, J.-W., Choi, J., et al. (2016) Enhanced Thermoelectric Performance of PEDOT: PSS/PANI-CSA Polymer Multilayer Structures. Energy \& Environmental Science, 9, 2806-2811. https://doi.org/10.1039/C5EE03063C

[26] Liu, F.J. (2008) Electrodeposition of Manganese Dioxide in Three-Dimensional Poly(3,4-Ethylenedioxythiophene)-Poly(Styrene Sulfonic Acid)-Polyaniline for Supercapacitor. Journal of Power Sources, 182, 383-388. https://doi.org/10.1016/j.jpowsour.2008.04.008

[27] Alexander, L., Klug, H.P., Alexander, L. and Klug, H.P. (1950) Determination of Crystallite Size with the XRay Spectrometer Determination of Crystallite Size with the X-Ray Spectrometer. Journal of Applied Physics, 21, 137-142. https://doi.org/10.1063/1.1699612

[28] Monshi, A., Foroughi, M.R. and Monshi, M.R. (2012) Modified Scherrer Equation to Estimate More Accurately Nano-Crystallite Size Using XRD. World Journal of Nano Science and Engineering, 2, 154-160. https://doi.org/10.4236/wjnse.2012.23020

[29] Hossain, M.F. and Takahashi, T. (2012) Comparative Study of CdS-Sensitized and Conventional Dye-Sensitized Solar Cells. 7 th International Conference on Electrical \& Computer Engineering, No. 3, 209-212.

[30] Eshaghi, A. and Aghaei, A.A.I.L. (2015) Effect of $\mathrm{TiO}_{2}$-Graphene Nanocomposite Photoanode on Dye-Sensitized Solar Cell Performance. Indian Academy of Sciences, 38, 1177-1182. 